\title{
Preoperative moderate thrombocytopenia is not associated with increased blood loss for low-risk cesarean section: a retrospective cohort study
}

\author{
Xiaohan $\mathrm{Xu}^{1}$, Yuelun Zhang ${ }^{2}$, Xuerong $\mathrm{Yu}^{1^{*}}$ and Yuguang Huang ${ }^{1}$
}

\begin{abstract}
Background: The occurrence of thrombocytopenia is as high as $7-12 \%$ in pregnancy, yet minimum platelet count safe for cesarean section remains unknown.

Methods: In this retrospective noninferior cohort study, we consecutively included patients undergoing cesarean section for a period of 6 years in a tertiary hospital and excluded patients at very high risk for excessive hemorrhage. The included patients with preoperative platelet count of $50-100 \times 10^{9} / \mathrm{L}$ were defined as the thrombocytopenic group. The control group were eligible patients with preoperative platelet count $>150 \times 10^{9} / \mathrm{L}$, matched to the thrombocytopenic group by age and operation timing in a 1:2 ratio. Mixed effect model was used to analyze the effect of thrombocytopenia based on a noninferiority assumption. The predefined noninferiority delta of bleeding was $50 \mathrm{~mL}$.

Results: There was no significant difference of the calculated blood loss between the thrombocytopenic and the control group (mean difference $=8.94,95 \% \mathrm{Cl}-28.34 \mathrm{~mL}$ to $46.09 \mathrm{~mL}$ ). No statistical difference was observed in the requirement for blood transfusion, visually estimated blood loss, or the incidence of adverse events between groups. Although there were more patients admitted to intensive care unit (odds ratio $=12,95 \% \mathrm{Cl} 2.69-53.62, p=$ 0.001 ) in the thrombocytopenic group, most of them required critical care for reasons other than hemorrhage. The thrombocytopenic group had longer length of hospital stay (mean difference $=0.40$ days, $95 \% \mathrm{Cl} 0.09-0.71, p=$ 0.011), but the difference was considered as clinically insignificant.
\end{abstract}

Conclusions: Preoperative moderate thrombocytopenia is not associated with increased blood loss, blood transfusion, or occurrence of adverse events in patients undergoing cesarean section in absence of additional bleeding risk.

Keywords: Thrombocytopenia, Blood loss, Cesarean section, Blood transfusion

\section{Introduction}

It has been recommended by guidelines that a preoperative platelet (PLT) count of $50 \times 10^{9} / \mathrm{L}$ or greater is safe for elective major surgery except neurosurgery or ophthalmic surgery involving the posterior segment of the eye $[1,2]$. However, the strength of such recommendation is weak due to the very low quality of evidence.

\footnotetext{
* Correspondence: yxr313@aliyun.com

${ }^{1}$ Department of Anesthesiology, Chinese Academy of Medical Sciences \&

Peking Union Medical College Hospital, Beijing 100730, China

Full list of author information is available at the end of the article
}

Since the bleeding risk may vary enormously among different types of surgery, it is more reliable to evaluate the tolerance of thrombocytopenia for each specific surgery type. To the best of our knowledge, there is scarce convincing evidence indicating the impact of preoperative moderate thrombocytopenia (PLT $50-100 \times 10^{9} / \mathrm{L}$ ) on blood loss for cesarean section (CS).

The occurrence of thrombocytopenia (PLT less than $150 \times 10^{9} / \mathrm{L}$ ) is as high as $7-12 \%$ in pregnancy [3]. Excessive blood loss at delivery is one of the leading causes for maternal mortality [4]. As a consequence, there has been

(c) The Author(s). 2019 Open Access This article is distributed under the terms of the Creative Commons Attribution 4.0 International License (http://creativecommons.org/licenses/by/4.0/), which permits unrestricted use, distribution, and reproduction in any medium, provided you give appropriate credit to the original author(s) and the source, provide a link to the Creative Commons license, and indicate if changes were made. The Creative Commons Public Domain Dedication waiver (http://creativecommons.org/publicdomain/zero/1.0/) applies to the data made available in this article, unless otherwise stated. 
considerable concern over the safety of thrombocytopenic patients undergoing CS in the past years. Recent publications indicate that delivery could be uneventful for most patients with idiopathic thrombocytopenic purpura (ITP) and gestational thrombocytopenia (GT) [5, 6]. On the contrary, patients with HELLP (hemolysis, elevated liver enzymes, low platelets) syndrome are at high risk for the sudden development of disseminated intravascular coagulation (DIC) and associated massive hemorrhage [7]. Given the heterogeneous etiology of thrombocytopenia, it is difficult to determine the indication for specific therapy to raise PLT count before CS. Actually, the minimum PLT count acceptable for CS differs greatly among medical centers, ranging from to $50-80 \times 10^{9} / \mathrm{L}[6,8,9]$. That is where the controversies arose and continued.

In this work, we designed this retrospective noninferior cohort study to evaluate the association of moderate thrombocytopenia with the calculated blood loss during and after CS. We hypothesized that moderate thrombocytopenia does not have clinically significant effect on blood loss.

\section{Methods}

\section{Study design and population}

We included consecutive patients undergoing CS from June 1, 2012 to 31 May 2018 in Peking Union Medical College Hospital, Beijing, China, which is a 2300-bed, university-affiliated, tertiary hospital. To reduce the impact of other factors that may affect blood loss or transfusion requirement, we excluded patients with: (1) abnormal coagulation test, anti-coagulation, or antiplatelet therapy within 1 week prior to surgery; (2) previous history of postpartum hemorrhage $(\mathrm{PPH})$ or platelet dysfunction; (3) abnormal placentation, including placenta previa, vasa previa, placenta accreta, and placental abruption; (4) preoperative spontaneous hemorrhage, active bleeding, or anemia (hemoglobin, $\mathrm{HGB}<100 \mathrm{~g} / \mathrm{L}$ ); (5) prophylactic platelet transfusion which was defined as platelet transfusion within 7 days prior to CS. The eligible patients whose PLT was $50-100 \times 10^{9} / \mathrm{L}$ in the last count of blood cell $(\mathrm{CBC})$ test before surgery were defined as thrombocytopenic group. The control group was selected from patients who also met the inclusion and exclusion criteria with preoperative PLT $>150 \times 10^{9} /$ L. Considering the total number of the control patients and the availability of the matching method, they were matched to cases in the thrombocytopenic group in a 1 : 2 ratio by age ( \pm 5 years) and operation timing (emergency vs. elective).

\section{Perioperative management}

The obstetrician team was consisted of a fellow, a chief resident, and a resident. Surgical techniques were standardized and for all the operations. Most patients underwent neuraxial anesthesia (NA), which was either spinal anesthesia, epidural anesthesia, or their combination. For the concerned about epidural hematoma, NA was contradicted if PLT count was less than $80 \times 10^{9} / \mathrm{L}$ [10]. General anesthesia (GA) would be initiated when NA was contradicted or not effective, or when there was no sufficient time for performing NA in urgent cases. Patients usually received lactated Ringer's solution $500-1000 \mathrm{ml}$ and colloid solution $500 \mathrm{ml}$ in the operating room. Crystalloid solution $1500 \mathrm{ml}$ was continued to be intravenously infused after the patients returned to the ward. Oral drinking was allowed 6 $h$ after surgery.

$\mathrm{CBC}$ test was routinely performed within 1 week prior to CS, and re-performed in $24-36 \mathrm{~h}$ after surgery. To prevent obstetric hemorrhage, a bolus dose of $10 \mathrm{IU}$ oxytocin was given intravenously over $1 \mathrm{~min}$, and another $10 \mathrm{IU}$ dissolved in $500 \mathrm{~mL}$ of $0.9 \%$ saline solution was infused after the uterus was sutured. RBC was transfused intraoperatively and/or postoperatively if the HGB level was lower than $80 \mathrm{~g} / \mathrm{L}$ or there were signs for uncontrollable ongoing hemorrhage. Fresh frozen plasma (FFP) and platelet would be transfused together if necessary.

\section{Data collection and outcomes}

Demographic and intraoperative information was collected from electronic anesthesia record, including age, body weight, height, gestational weeks, operation duration, birth weight, and anesthesia method.

The calculated blood loss was the primary outcome. Hematocrit (HCT) in the last preoperative $\mathrm{CBC}$ test and in the first postoperative $\mathrm{CBC}$ test was recorded. We used the following equation [11] for blood loss calculation.

$$
\begin{aligned}
& \text { Calculated blood loss } / m l=\text { estimated blood volume } / \mathrm{ml} \\
& \times \text { precentage of HCT derease } \\
& \text { Estimated blood volume } / m l=0.75 \times[(\text { height } / m \times 1968.50) \\
& +(\text { weight } / \mathrm{kg} \times 55.12)] \\
& \text { Precentage of HCT decrease }=\text { (preoperative HCT } \\
& \text { - postoperative HCT) } \\
& \text { / preoperative HCT }
\end{aligned}
$$

For patients who received $\mathrm{RBC}$ transfusion during surgery, the blood loss before transfusion can be calculated based on the change between preoperative HCT and pre-transfusion HCT, while similarly the blood loss after transfusion can be calculated by post-transfusion HCT and postoperative HCT. Their total blood loss was the sum of these two parts.

The secondary outcomes were observed over a period of postoperative hospitalization. We extracted the data from medical records about: (1) the requirement for blood transfusion, (2) visually estimated intraoperative blood loss, (3) surgical site bleeding requiring a second invasive therapy (open surgery or interventional embolization), (4) 
the occurrence of postoperative adverse events (infection, delayed wound healing, cardiac event, cerebrovascular event, thromboembolism event), (5) the requirement for postoperative intensive care unit (ICU) stay, (6) the length of hospital stay, (7) all-cause mortality.

\section{Statistical analysis}

We described the baseline characteristics of the eligible patients using descriptive analysis. Continuous data were expressed as mean (standard difference) (normally distributed data) or median (quartiles) (non-normally distributed data). Patients' baseline characteristics were compared between groups using the standardized difference and $p$ value, where standardized difference smaller than 0.2 or $p$ value greater than 0.05 was considered as acceptable deviation between groups. Unbalanced variables at baseline were included in the mixed-effect model to adjust for the potential confounding effect.

The primary outcome of blood loss was analyzed in a noninferior fashion. Based on clinical experience, we used $50 \mathrm{~mL}$ as the clinically significant noninferior delta. The hypothesis was that the thrombocytopenic group was non-inferior to the control group for $50 \mathrm{ml}$ blood loss. Considering the matched design between the exposed and the control groups, we used the mixed-effect model to analyze the effect of preoperative thrombocytopenia, in which the dependent variable was the calculated blood loss. Blood measures at individual level were analyzed as lower level of data while the effect of matched pairs was analyzed as higher level of data in the mixed effected model. The mean difference of blood loss between the thrombocytopenic and the control groups and the standard error of the mean difference from the mixed-effect model was used to calculate the two-side 95\% confidence interval (CI), which would be compared with the predefined noninferiority delta.

If the upper bound of the noninferior 95\% CI was smaller than $50 \mathrm{~mL}$, we rejected the null hypothesis and concluded that the blood loss in the thrombocytopenic group was not larger than in the control group.

The effect of thrombocytopenia on blood loss may be influenced by other confounding factors. American Society of Anesthesiologists (ASA) classification of physical status, body mass index (BMI), gestational weeks, previous uterine scar, neonatal macrosomia, multiple pregnancies, anesthesia method and operation duration were regarded as potential confounders based on previous publications. We checked if their distributions were balanced between the thrombocytopenia and the control groups, and unbalanced factors were included in the adjusted models.

We used the mixed-effect model to compare visually estimated blood loss and the length of postoperative hospital stay between the thrombocytopenic group and the control group due to its non-normal distribution. Conditional logistic regression was used to compare the other binary secondary outcomes between the two groups.

Mixed-effect and conditional logistic regression models were built in $\mathrm{R}$ (version 3.4.4) using the "Ime4" and "survival" packages. Other analyses were conducted in SPSS (version 13, SPSS, Inc., Chicago, IL, USA).

Since the eligible participants in our center during the study period were limited, we used the sample size in the analysis to calculate the statistical power based on the noninferiority assumption. Considering the clinical relevance, we employed the primary outcome and calculated blood loss as the key outcome in the power calculation. Probability of type I error was set to two-side 0.05 . Sample size was 155 in the thrombocytopenic group and 310 in the control group. The noninferiority delta was $50 \mathrm{~mL}$ considering the clinical relevance. Based on the above parameters, the power of our analysis was $85.86 \%$.

\section{Results}

\section{Baseline characteristics}

A total of 7577 patients received CS over the six-year study period. 481 of them were excluded for the reasons shown in Fig. 1. Among the remaining 7096 cases, 155 patients had preoperative PLT $50-100 \times$ $10^{9} / \mathrm{L}$ and thus were included in the thrombocytopenic group. Matched by a ratio of 1:2, 310 patients with preoperative $\mathrm{PLT}>150 \times 10^{9} / \mathrm{L}$ were included in the control group.

The preoperative platelet count was $(71.9 \pm 13.0) \times$ $10^{9} / \mathrm{L}$ in the thrombocytopenic group and $(203.6 \pm$ $41.5) \times 10^{9} / \mathrm{L}$ in the control group. The etiologies for thrombocytopenia were gestational thrombocytopenia (GT) $(70,45.2 \%)$, pre-eclampsia $(22,14.2 \%)$, idiopathic thrombocytopenic purpura (ITP) $(19,12.3 \%)$, systemic lupus erythematosus (SLE) (17, 11.0\%), mixed connective tissue disease $(3,1.9 \%)$, myelodysplastic syndrome $(3,1.9 \%)$, hypersplenism $(1,0.65 \%)$ and thrombotic thrombocytopenic purpura (1, 0.65\%). The etiology was unknown for the rest of patients. Baseline characteristics between the two groups are displayed in Table 1 . We did not find significant difference in age, ASA, previous uterine scar, neonatal macrosomia, multiple pregnancies, operation timing and operation duration between groups, whereas BMI (standardized difference $=0.34, p=0.001$ ), gestational weeks (standardized difference $=0.24, p=0.018$ ) and anesthesia method (standardized difference $=0.63, p<$ 0.001 ) were not balanced in the two groups. 


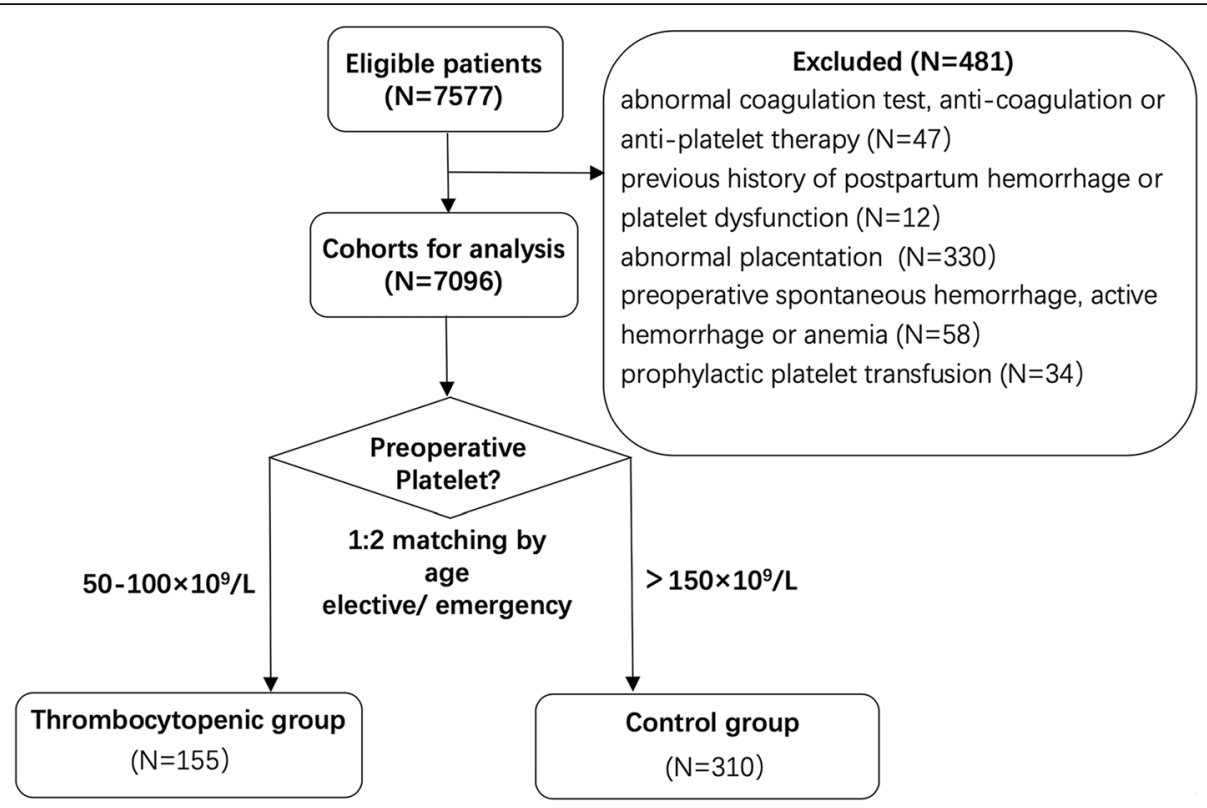

Fig. 1 Study design and group allocation. Abbreviation: PLT, platelet

\section{Primary outcome}

The calculated blood loss was $417.8 \pm 194.6 \mathrm{ml}$ in the thrombocytopenic group and $414.5 \pm 182.9 \mathrm{ml}$ in the control group. The coefficient of thrombocytopenia effect in the mixed-effect model was 3.3, indicating that the calculated blood loss in the thrombocytopenic group was $3.3 \mathrm{~mL}$ higher than that in the control group (Table 2). According to the formula in the method section, the upper bound of the two-side $95 \% \mathrm{CI}$ of the calculated blood loss was $37.67 \mathrm{~mL}$, lower than the predefined noninferiority delta $(50 \mathrm{~mL})$. We built the following 5 models to examine the independent effect of thrombocytopenia on blood loss. Besides the unbalanced factors- BMI, gestational weeks and anesthesia method, we also include operation duration into models, based on our clinical experiences.

Model 1: blood loss thrombocytopenia

Model 2: blood loss $\sim$ thrombocytopenia + operation duration

Model 3: blood loss thrombocytopenia + operation duration + BMI

Model 4: blood loss $\sim$ thrombocytopenia + operation duration + BMI + anesthesia method

Model 5: blood loss $\sim$ thrombocytopenia + operation duration + BMI + anesthesia method + gestational weeks

The fifth mixed-effect model that includes thrombocytopenia, operation duration, BMI, anesthesia method and gestational weeks yielded a coefficient of 8.94, indicating that the calculated blood loss in the thrombocytopenic group was $8.94 \mathrm{~mL}$ (95\% CI - 28.34 to $46.09 \mathrm{~mL}$ ) greater than that in the control group. In summary, the noninferiority assumption was claimed in all the 5 models.

\section{Secondary outcomes}

The descriptive analysis and comparison of secondary outcomes was demonstrated in Table 3. Five patients (3.2\%) and seven $(2.3 \%)$ patients received transfusion in the thrombocytopenic and the control group respectively. Among them, one in the thrombocytopenic group and one in the control group with a calculated blood loss of about $1600 \mathrm{ml}$ received $4 \mathrm{U}$ RBC and $800 \mathrm{ml}$ FFP. Additionally, the former one also received $2 \mathrm{U}$ platelet. Two patients (one for each group) had a calculated blood loss of 1000-1500 $\mathrm{ml}$ and received $2 \mathrm{U}$ RBC along with $400 \mathrm{ml}$ FFP. The remaining eight patients only received $2 \mathrm{U}$ RBC. There were two (1.3\%) cases of postoperative adverse events in the thrombocytopenic group, including one right heart failure secondary to pulmonary hypertension and one suspected infection (febrile lasting for more than $24 \mathrm{~h}$ with no pathogenic evidence). The two $(0.65 \%)$ cases of adverse events in the control group were suspected infection and venous thromboembolism. Twelve $(7.7 \%)$ in the thrombocytopenic group and two $(0.65 \%)$ in the control group went to ICU after surgery, including the four who required $\mathrm{RBC}$ and FFP transfusion and the one with heart failure mentioned above. The remaining nine of them were all patients with autoimmune disease from the thrombocytopenic group. They spent 1-3 days in ICU for the concern about the progression of lupus nephropathy or the relapse of lupus 
Table 1 Baseline Characteristics

\begin{tabular}{|c|c|c|c|c|}
\hline & Thrombocytopenic Group $(n=155)$ & Control Group $(n=310)$ & Standardized difference & $p$ value \\
\hline Age (yrs) & $31.5 \pm 4.5$ & $31.5 \pm 4.3$ & 0.01 & 0.905 \\
\hline $\mathrm{BMI}\left(\mathrm{kg} / \mathrm{m}^{2}\right)$ & $26.2 \pm 3.0$ & $27.1 \pm 2.8$ & 0.34 & $0.001^{*}$ \\
\hline ASA & & & 0.12 & 0.271 \\
\hline ॥ & $134(86.5 \%)$ & $280(90.3 \%)$ & & \\
\hline III & $21(13.5 \%)$ & $30(9.7 \%)$ & & \\
\hline Gestational weeks & $37.8 \pm 1.4$ & $38.1 \pm 1.3$ & 0.24 & $0.018^{*}$ \\
\hline Birth weight (g) & $3024.3 \pm 468.3$ & $3059.6 \pm 452.1$ & 0.08 & 0.438 \\
\hline Previous uterine scar & & & 0.01 & 1.000 \\
\hline Yes & $28(18.1 \%)$ & $55(17.7 \%)$ & & \\
\hline No & $127(81.9 \%)$ & $255(82.3 \%)$ & & \\
\hline Neonatal macrosomia & & & 0.06 & 0.716 \\
\hline Yes & $7(4.5 \%)$ & $18(5.8 \%)$ & & \\
\hline No & $148(95.5 \%)$ & $292(94.2 \%)$ & & \\
\hline Multiple pregnancies & & & 0.03 & 0.938 \\
\hline Yes & $8(5.2 \%)$ & $14(4.5 \%)$ & & \\
\hline No & $147(94.8 \%)$ & $296(95.5 \%)$ & & \\
\hline Anesthesia method & & & 0.63 & $<0.001^{*}$ \\
\hline NA & $120(77.4 \%)$ & $302(97.4 \%)$ & & \\
\hline GA & $35(22.6 \%)$ & $8(2.6 \%)$ & & \\
\hline Operation timing & & & 0.00 & 1.000 \\
\hline Elective & $86(55.5 \%)$ & $172(55.5 \%)$ & & \\
\hline Emergency & 69 (44.5\%) & $138(44.5 \%)$ & & \\
\hline Operation duration (min) & $60.7 \pm 16.1$ & $57.9 \pm 14.3$ & 0.07 & 0.474 \\
\hline Preoperative PLT $\left(\times 10^{9} / \mathrm{L}\right)$ & $71.9 \pm 13.0$ & $203.6 \pm 41.5$ & 4.29 & $<0.001^{*}$ \\
\hline
\end{tabular}

Abbreviations: BMI body mass index, ASA American Society of Anesthesiologists classification of physical status, NA neuraxial anesthesia, GA general anesthesia Values are expressed as mean \pm SD or number (percentage) of patients. Patients' baseline characteristics were compared between groups using the standardized difference and $p$ value, where a standardized difference smaller than 0.2 and $p$ greater than 0.05 was considered as acceptable deviation between groups. The two groups were balanced in age, operation timing, ASA, the presence of underlying risk factors and operation duration. On the contrary, they were not balanced in BMl, gestational weeks and anesthesia method

Table 2 Effect of Thrombocytopenia for the Calculated Blood Loss in the Mixed-effect Model in 465 Patients

\begin{tabular}{ll}
\hline Model $^{a}$ & $95 \%$ confidence interval (ml) \\
\hline $1^{b}$ & -31.06 to 37.67 \\
$2^{b}$ & -31.09 to 37.69 \\
$3^{b}$ & -29.32 to 40.28 \\
$4^{b}$ & -29.05 to 45.17 \\
$5^{b}$ & -28.34 to 46.09 \\
\hline
\end{tabular}

Abbreviations: $B M I$ body mass index;

a The reference group in the mixed-effect models was the control group

${ }^{b}$ Model 1: blood loss thrombocytopenia, Model 2: blood loss thrombocytopenia + operation duration, Model 3: blood loss thrombocytopenia + operation duration + BMI, Model 4: blood loss thrombocytopenia + operation duration + BMI + anesthesia method, Model 5 : blood loss $\sim$ thrombocytopenia + operation duration + BMI + anesthesia method + gestational weeks encephalopathy. No invasive hemostatic intervention or death was observed in both groups.

No statistical difference was observed regarding the requirement for blood transfusion, visually estimated intraoperative blood loss, or the incidence of adverse events between groups (Table 3). However, there were more patients admitted to ICU (odds ratio $12.00,95 \% \mathrm{CI}$ 2.69 to 53.62, $p=0.001$ ) and longer length of hospital stay (mean difference $=0.40$ day, $95 \%$ CI 0.09 to 0.71 , $p=0.011)$ in the thrombocytopenic group.

\section{Discussion}

In the present study, we respectively reviewed the calculated blood loss, visually estimated blood loss, blood transfusion, invasive hemostatic intervention, postoperative adverse events, ICU stay, hospital stay and all-cause mortality in low-risk CS patients with preoperative PLT $50-100 \times 10^{9} / \mathrm{L}$ over a period of 6 years in a tertiary medical center. We found that preoperative moderate 
Table 3 Descriptive analysis and Comparison of Secondary Outcomes

\begin{tabular}{|c|c|c|c|c|c|}
\hline Variable & Thrombocytopenic Group $(n=155)$ & Control Group $(n=310)$ & Estimate (OR or mean difference) & $95 \% \mathrm{Cl}$ & $p$ value \\
\hline Blood transfusion & $5(3.2 \%)$ & $7(2.3 \%)$ & 1.55 & $0.43-5.58$ & 0.505 \\
\hline Visually estimated blood loss & $315.8 \pm 150.0$ & $297.6 \pm 126.6$ & 18.23 & $-7.07-43.52$ & 0.158 \\
\hline Hemostatic therapy & $0(0 \%)$ & $0(0 \%)$ & / & / & / \\
\hline Adverse event & $2(1.3 \%)$ & $2(0.65 \%)$ & 2.00 & $0.28-14.20$ & 0.488 \\
\hline ICU stay & $12(7.7 \%)$ & $2(0.65 \%)$ & 12.00 & $2.69-53.62$ & $0.001^{\mathrm{a}}$ \\
\hline Length of hospital stay & $3[3,4]$ & $3[3,4]$ & 0.40 & $0.09-0.71$ & $0.011^{\mathrm{a}}$ \\
\hline All-cause mortality & $0(0 \%)$ & $0(0 \%)$ & / & / & / \\
\hline
\end{tabular}

Abbreviations: ICU intensive care unit, $O R$ odds ratio, $\mathrm{Cl}$ confidence interval;

Continuous data was expressed as mean (SD) (normally distributed data) or median (quartiles) (non-normally distributed data. Categorical data was expressed as number (percentage). Visually estimated blood loss and the length of postoperative hospital stay was compared by mixed-effect model. Other parameters were compared by conditional logistic regression. ${ }^{\text {a }}$ Significant difference

thrombocytopenia is not associated with increased blood loss, requirement for blood transfusion, or incidence of adverse events.

It has been reported that the leading causes for thrombocytopenia are GT, pre-eclampsia and ITP [12], which are consistent with our data. GT is resulted from hemodilution and increased platelet turnover during pregnancy [13], and requires no treatment as it is not associated with increased bleeding risk or altered delivery mode [10]. Studies in ITP complicating pregnancy demonstrated that severe morbidity or mortality was uncommon, despite the moderate drop of PLT $[14,15]$. Hence, there has been a trend towards a more conservative management $[16,17]$, even without much information about the blood loss at delivery in thrombocytopenic pregnant patients.

Guidelines recommend a PLT threshold of $50 \times 10^{9} / \mathrm{L}$ prior to major surgery and $100 \times 10^{9} / \mathrm{L}$ for neurosurgery and ophthalmic surgery $[1,2,18,19]$. However, it has been found that a preoperative platelet count of 50 $100 \times 10^{9} / \mathrm{L}$ is associated with increased requirement for blood transfusion and 30-day mortality after non-cardiac surgery [20]. Since the minimum PLT count safe for CS remains unclear, decisions on whether to raise PLT count before CS are often based on physicians' clinical experience rather than high-quality evidence. Thromboelastography has been indicated to be a good predictor of bleeding risk in patients with severe thrombocytopenia $\left(\mathrm{PLT}<10 \times 10^{9} / \mathrm{L}\right)$ caused by hematologic malignancies [21]. Nevertheless, its predictive value in patients with PLT $50-100 \times 10^{9} / \mathrm{L}$ is still open to doubt, and the high cost may limit its use.

Our findings elucidate that patients with preoperative moderate thrombocytopenia had no more blood loss, blood product transfusion, or postoperative adverse events than the ones with normal PLT count. Based on these findings, we could cautiously speculate that raising PLT count to above $100 \times 10^{9} / \mathrm{L}$ before low-risk CS might bring little obvious benefits to patients without massive hemorrhage. Preoperative PLT transfusion is commonly used to rapidly raise PLT count in thrombocytopenic patients. However, such prophylactic transfusion might be unnecessary for CS patients with PLT 50$100 \times 10^{9} / \mathrm{L}$ in absence of additional bleeding risk. In this way, a series of transfusion-associated risks could be reduced, including febrile, allergic reactions, arrhythmia, transmissible infections, hemolysis, auto-antibody production, transfusion related acute lung injury and immunomodulation [2, 22].

The blood loss was calculated based on pre- and post-operative HCT. Its inaccuracy mainly results from the change of circulating blood volume [23], which could be minimized in our study by applying comparable infusion strategy to each patient if there was no massive hemorrhage. The data of postoperative HCT was acquired from the results of CBC test performed 24-36 $\mathrm{h}$ after surgery, thus there was enough time for fluid shift and volume balance [24]. Based on the recommendations by World Health Organization (WHO), primary PPH is defined as blood loss more than $500 \mathrm{ml}$ within $24 \mathrm{~h}$ after delivery [25]. Since most peripartum hemorrhage occurs during or within the first $4 \mathrm{~h}$ posterior to delivery [26], the calculated blood loss measured $24-36 \mathrm{~h}$ postoperatively in this study is reflective of the above high-risk period. Although other methods could also be used in blood loss estimation, their limitations cannot be ignored. In our study, the visually estimated blood loss is less than the calculated value in both groups. This is consistent with the data in previous publications, indicating that the blood loss could be highly underestimated by visual estimation [27-29]. Gravimetric method has also been demonstrated low accuracy because of the invisible interference of the weight of amniotic fluid [30, 31]. A novel mobile application, photographic colorimetric system, has been proven to be more reliable, but it cannot be accessed in most countries [32, 33].

There were significantly more patients admitted to ICU in the thrombocytopenic group than in the control group. However, only two (16.7\%) of them went to ICU for massive hemorrhage. In fact, most $(9 / 12,75 \%)$ of them had severe autoimmune disease with multi-organ 
involvement prior to surgery. It has been widely accepted that pregnancy could be a trigger for an increase in SLE activity [34]. Furthermore, thrombocytopenia in SLE patients during pregnancy is also a predictor for severe organ damage and poor prognosis [35]. Patients in the thrombocytopenic group also spent statistically more days in hospital after surgery, whereas the mean difference between groups was 0.40 day, which could be considered as clinically insignificant.

According to prior publications, well-recognized risk factors for excessive hemorrhage or blood transfusion of CS are: low BMI, prolonged operation duration, emergency, abnormal placentation, previous uterine scar, multiple pregnancies, neonatal macrosomia, placenta previa, placental abruption, preoperative anemia and general anesthesia [36-42]. In our study, we tried to control the confounders in three ways. First, we excluded patients with coagulopathy, platelet dysfunction, bleeding tendency, history of PPH, abnormal placentation and preoperative anemia. Second, the two groups were well-balanced in age and surgery timing (emergency or elective) at baseline by using matching approach. Third, there was significantly higher general anesthesia rate in the thrombocytopenia group than control group ( $22.6 \%$ vs $2.6 \%)$. In view of the possible association of general anesthesia with uterine atony and increased hemorrhage [43], anesthesia method may represent a significant confounder. Therefore, we included anesthesia method, along with BMI, operation duration and gestational weeks in the mixed-effect model. As a result, the upper bound of the two-side 95\% CI of the calculated blood loss was still no greater than the predefined noninferiority delta.

Being observational and retrospective by nature, we cannot draw causal relationships and there could be inaccuracy in medical records. Furthermore, our study was subject to the following aspects of limitations. First, the calculated blood loss and transfusion rate is slightly lower than that reported previously $[6,13,16]$, possibly due to the exclusion of patients with risk factors for excessive hemorrhage in our study. Consequently, the conclusion could not be hastily applied to patients at higher risk of massive blood loss. Additionally, since the average blood loss was within normal range in both groups, the potential effects of preoperative thrombocytopenia in patients who experienced primary $\mathrm{PPH}$ might be masked. To address this possibility, we conducted an exploratory subgroup analysis in patients with calculated blood loss $>500 \mathrm{ml}$. In this subgroup, the calculated blood loss was $679.7 \pm 228.0 \mathrm{ml}$ and $644.5 \pm 175.7 \mathrm{ml}$ in thrombocytopenic group $(n=34,21.9 \%)$ and control group $(n=79,25.5 \%)$, respectively. No significant difference was observed between groups (Student ttest $p=0.375$ ). Second, considering a small sample size, the incidence of adverse event is very low and no hemostatic intervention or mortality was observed. Although we found no statistical differences between groups, perhaps there is still insufficient evidence to determine the impact of thrombocytopenia on these secondary outcomes. Third, our data was collected from a tertiary hospital, where patients were carefully evaluated during pregnancy, and the obstetrician team were experienced and skilled. Therefore, it is unknown whether our findings could also be instructive in primary medical settings with limited resources. Finally, we did not assess the clinical outcomes of neonates. Thus, the impact of maternal thrombocytopenia on infants' PLT count at birth needs to be further explored.

\section{Conclusion}

In conclusion, preoperative moderate thrombocytopenia (PLT $50-100 \times 10^{9} / \mathrm{L}$ ) does not increase the risk of blood loss, the requirement for blood transfusion, or the occurrence of adverse events in patients undergoing CS in absence of other risk factors for excessive hemorrhage. A restrictive preoperative PLT threshold might optimize blood utilization without worsening maternal outcomes. Prospective observational studies with larger sample size and randomized controlled trials are required to better refine the preoperative prophylactic platelet transfusion strategy.

\section{Abbreviations}

ASA: American Society of Anesthesiologists classification; BMl: Body mass index; CBC: Count of blood cell; Cl: Confidence interval; CS: Cesarean section; DIC: Disseminated intravascular coagulation; FFP: Fresh frozen plasma;

GA: General anesthesia; GT: Gestational thrombocytopenia; HCT: Hematocrit; HELLP: Hemolysis, elevated liver enzymes, low platelets; HGB: Hemoglobin;

ICU: Intensive care unit; ITP: Idiopathic thrombocytopenic purpura;

NA: Neuraxial anesthesia; PLT: Platelet; PPH: Postpartum hemorrhage;

RBC: Red blood cell; SLE: Systemic lupus erythematosus

\section{Acknowledgements}

Not applicable

\section{Authors' contributions}

$X X$ collected the data and was a major contributor in writing the manuscript. $Y Z$ conducted the statistical analysis. $X Y$ designed the research protocol and revised the manuscript. YH provided advice and communicated with other departments. All authors read and approved the final manuscript.

\section{Funding}

This study was sponsored by Chinese Academy of Medical Science (CAMS) Innovation Fund for Medical Sciences (CIFMS) (2016-12M-3-024). The funding body had no role in the design of the study; in data collection, analysis, or interpretation; or in the writing of the manuscript.

\section{Availability of data and materials}

The datasets generated and analyzed during the current study are available from the corresponding author on reasonable request.

Ethics approval and consent to participate

The research protocol was approved by the institutional review board of Peking Union Medical College Hospital (reference number: S-K517). Patient 
consent for participation was waived by the ethics committee due to the retrospective nature of the study.

\section{Consent for publication}

Not applicable

\section{Competing interests}

The authors declare that they have no competing interests.

\section{Author details}

'Department of Anesthesiology, Chinese Academy of Medical Sciences \& Peking Union Medical College Hospital, Beijing 100730, China. ${ }^{2}$ Central Research Laboratory, Chinese Academy of Medical Sciences \& Peking Union Medical College Hospital, Beijing 100730, China.

Received: 15 October 2018 Accepted: 19 July 2019

Published online: 29 July 2019

\section{References}

1. Kaufman RM, Djulbegovic B, Gernsheimer T, Kleinman S, Tinmouth AT, Capocelli KE, Cipolle MD, Cohn CS, Fung MK, Grossman BJ, et al. Platelet transfusion: a clinical practice guideline from the AABB. Ann Intern Med. 2015;162(3):205-13.

2. Estcourt LJ, Birchall J, Allard S, Bassey SJ, Hersey P, Kerr JP, Mumford AD, Stanworth SJ, Tinegate H. Guidelines for the use of platelet transfusions. Br J Haematol. 2017:176(3):365-94.

3. Gernsheimer TB. Thrombocytopenia in pregnancy: is this immune thrombocytopenia or...? Hematology Am Soc Hematol Educ Program. 2012; 2012:198-202

4. Clark SL, Belfort MA, Dildy GA, Herbst MA, Meyers JA, Hankins GD. Maternal death in the 21 st century: causes, prevention, and relationship to cesarean delivery. Am J Obstet Gynecol. 2008;199(1):36.e31-5 discussion 91-32. e37-11.

5. Webert KE, Mittal R, Sigouin C, Heddle NM, Kelton JG. A retrospective 11year analysis of obstetric patients with idiopathic thrombocytopenic purpura. Blood. 2003;102(13):4306-11.

6. Kim BJ, Kim HS, Kim JH, Lee KY. Moderate to severe thrombocytopenia during pregnancy: a single institutional experience. Indian J Hematol Blood Transfus. 2017:33(4):581-5.

7. Cines DB, Levine LD. Thrombocytopenia in pregnancy. Hematol Am Soc Hematol Educ Program. 2017:2017(1):144-51.

8. Nicolescu A, Vladareanu AM, Voican I, Onisai M, Vladareanu R. Therapeutic options for immune thrombocytopenia (ITP) during pregnancy. Maedica. 2013;8(2):182-8

9. Gernsheimer T, James AH, Stasi R. How I treat thrombocytopenia in pregnancy. Blood. 2013:121(1):38-47.

10. Myers B. Diagnosis and management of maternal thrombocytopenia in pregnancy. Br J Haematol. 2012;158(1):3-15.

11. Gluck O, Mizrachi Y, Kovo M, Divon M, Bar J, Weiner E. Major underestimation and overestimation of visual blood loss during cesarean deliveries: can they be predicted? Arch Gynecol Obstet. 2017;296(5):907-13.

12. Chen Z, Liang MY, Wang JL. Etiology and clinical characteristics of pregnancy-emerged thrombocytopenia. Zhonghua Fu Chan Ke Za Zhi. 2011:46(11):834-9.

13. Bergmann F, Rath W. The differential diagnosis of thrombocytopenia in pregnancy. Dtsch Arztebl Int. 2015;112(47):795-802.

14. Kelton JG. Idiopathic thrombocytopenic purpura complicating pregnancy. Blood Rev. 2002;16(1):43-6

15. Won YW, Moon W, Yun YS, Oh HS, Choi JH, Lee YY, Kim IS, Choi IY, Ahn MJ. Clinical aspects of pregnancy and delivery in patients with chronic idiopathic thrombocytopenic purpura (ITP). Korean J Intern Med. 2005;20(2):129-34

16. Gill KK, Kelton JG. Management of idiopathic thrombocytopenic purpura in pregnancy. Semin Hematol. 2000;37(3):275-89.

17. Lee LH. Idiopathic thrombocytopenia in pregnancy. Ann Acad Med Singap. 2002:31(3):335-9.

18. Slichter SJ. Evidence-based platelet transfusion guidelines. Hematology Am Soc Hematol Educ Program. 2007;2007(1):172-8.

19. Samama CM, Djoudi R, Lecompte T, Nathan N, Schved JF. Perioperative platelet transfusion. Recommendations of the French health products safety agency (AFSSAPS) 2003. Minerva Anestesiol. 2006;72(6):447-52.
20. Glance LG, Blumberg N, Eaton MP, Lustik SJ, Osler TM, Wissler R, Zollo $R$, Karcz M, Feng C, Dick AW. Preoperative thrombocytopenia and postoperative outcomes after noncardiac surgery. Anesthesiology. 2014; 120(1):62-75.

21. Kim SY, Gu JY, Yoo HJ, Kim JE, Jang S, Choe S, Koh Y, Kim I, Kim HK. Benefits of Thromboelastography and thrombin generation assay for bleeding prediction in patients with thrombocytopenia or hematologic malignancies. Ann Lab Med. 2017;37(6):484-93.

22. Kaufman RM, Assmann SF, Triulzi DJ, Strauss RG, Ness P, Granger S, Slichter SJ. Transfusion-related adverse events in the platelet dose study. Transfusion. 2015:55(1):144-53.

23. Schorn MN. Measurement of blood loss: review of the literature. J Midwifery Womens Health. 2010:55(1):20-7.

24. Zhu G, Li Y, Ru G, Ding Q. Comparison of the hemodynamics and dynamics of fluid shift of Ringer's solution before surgery in children and adults. Exp Ther Med. 2017;13(6):3146-52

25. Tuncalp O, Souza JP, Gulmezoglu M. New WHO recommendations on prevention and treatment of postpartum hemorrhage. Int J Gynaecol Obstet. 2013:123(3):254-6.

26. Lier H, von Heymann C, Korte W, Schlembach D. Peripartum Haemorrhage: Haemostatic aspects of the new German PPH guideline. Transfus Med Hemother. 2018;45(2):127-35.

27. Rath WH. Postpartum hemorrhage--update on problems of definitions and diagnosis. Acta Obstet Gynecol Scand. 2011;90(5):421-8.

28. Lilley G, Burkett-St-Laurent D, Precious E, Bruynseels D, Kaye A, Sanders J, Alikhan R, Collins PW, Hall JE, Collis RE. Measurement of blood loss during postpartum haemorrhage. Int J Obstet Anesth. 2015;24(1):8-14

29. Yoong W, Karavolos S, Damodaram M, Madgwick K, Milestone N, AlHabib A, Fakokunde A, Okolo S. Observer accuracy and reproducibility of visual estimation of blood loss in obstetrics: how accurate and consistent are health-care professionals? Arch Gynecol Obstet. 2010; 281(2):207-13.

30. Golmakani N, Khaleghinezhad K, Dadgar S, Hashempor M, Baharian N. Comparing the estimation of postpartum hemorrhage using the weighting method and National Guideline with the postpartum hemorrhage estimation by midwives. Iran J Nurs Midwifery Res. 2015; 20(4):471-5.

31. Al Kadri HM, Al Anazi BK, Tamim HM. Visual estimation versus gravimetric measurement of postpartum blood loss: a prospective cohort study. Arch Gynecol Obstet. 2011;283(6):1207-13.

32. Doctorvaladan SV, Jelks AT, Hsieh EW, Thurer RL, Zakowski MI, Lagrew DC. Accuracy of blood loss measurement during cesarean delivery. AJP Rep. 2017;7(2):e93-e100.

33. Rubenstein AF, Zamudio S, Al-Khan A, Douglas C, Sledge S, Tully G, Thurer RL. Clinical experience with the implementation of accurate measurement of blood loss during cesarean delivery: influences on hemorrhage recognition and allogeneic transfusion. Am J Perinatol. 2018:35(7):655-9.

34. Liu J, Zhao Y, Song Y, Zhang W, Bian X, Yang J, Liu D, Zeng X, Zhang F. Pregnancy in women with systemic lupus erythematosus: a retrospective study of 111 pregnancies in Chinese women. J Matern Fetal Neonatal Med. 2012;25(3):261-6.

35. Xu X, Liang MY, Wang $J$, Chen S. Clinical features and outcome of pregnancy with SLE-associated thrombocytopenia. J Maternal Fetal Neonatal Med. 2016;29(5):789-94.

36. Akinlusi FM, Rabiu KA, Durojaiye IA, Adewunmi AA, Ottun TA, Oshodi YA. Caesarean delivery-related blood transfusion: correlates in a tertiary hospital in Southwest Nigeria. BMC Pregnancy Childbirth. 2018;18(1):24.

37. Pearson GA, Mackenzie IZ. Blood loss and blood transfusion at caesarean section: a prospective observational study covering 30 years. Eur J Obstet Gynecol Reprod Biol. 2014;181:72-7.

38. Kolas T, Oian P, Skjeldestad FE. Risks for peroperative excessive blood loss in cesarean delivery. Acta Obstet Gynecol Scand. 2010;89(5):658-63.

39. Al-Zirqi I, Vangen S, Forsen L, Stray-Pedersen B. Prevalence and risk factors of severe obstetric haemorrhage. BJOG. 2008;115(10):1265-72.

40. Rouse DJ, MacPherson C, Landon M, Varner MW, Leveno KJ, Moawad AH, Spong CY, Caritis SN, Meis PJ, Wapner RJ, et al. Blood transfusion and cesarean delivery. Obstet Gynecol. 2006;108(4):891-7.

41. Butwick AJ, Ramachandran B, Hegde P, Riley ET, El-Sayed YY, Nelson LM. Risk factors for severe postpartum hemorrhage after cesarean delivery: case-control studies. Anesth Analg. 2017;125(2):523-32. 
42. Nyflot LT, Sandven I, Stray-Pedersen B, Pettersen S, Al-Zirqi I, Rosenberg M, Jacobsen AF, Vangen S. Risk factors for severe postpartum hemorrhage: a case-control study. BMC Pregnancy Childbirth. 2017;17(1):17.

43. Aiken CE, Aiken AR, Cole JC, Brockelsby JC, Bamber JH. Maternal and fetal outcomes following unplanned conversion to general anesthetic at elective cesarean section. J Perinatol. 2015;35(9):695-9.

\section{Publisher's Note}

Springer Nature remains neutral with regard to jurisdictional claims in published maps and institutional affiliations.

Ready to submit your research? Choose BMC and benefit from:

- fast, convenient online submission

- thorough peer review by experienced researchers in your field

- rapid publication on acceptance

- support for research data, including large and complex data types

- gold Open Access which fosters wider collaboration and increased citations

- maximum visibility for your research: over $100 \mathrm{M}$ website views per year

At BMC, research is always in progress.

Learn more biomedcentral.com/submissions 